\title{
An overview of the Geoengineering Model Intercomparison Project (GeoMIP)
}

\author{
Ben Kravitz, ${ }^{1}$ Alan Robock, ${ }^{2}$ Piers M. Forster, ${ }^{3}$ James M. Haywood, ${ }^{4,5}$ \\ Mark G. Lawrence, ${ }^{6}$ and Hauke Schmidt ${ }^{7}$ \\ Received 24 July 2013; revised 1 October 2013; accepted 7 October 2013; published 12 December 2013.
}

[1] The Geoengineering Model Intercomparison Project (GeoMIP) was designed to determine robust climate system model responses to solar geoengineering. GeoMIP currently consists of four standardized simulations involving reduction of insolation or increased amounts of stratospheric sulfate aerosols. Three more experiments involving marine cloud brightening are planned. This project has improved confidence in the expected climate effects of geoengineering in several key areas, such as the effects of geoengineering on spatial patterns of temperature and the spatial distribution of precipitation, especially extreme precipitation events. However, GeoMIP has also highlighted several important research gaps, such as the effects on terrestrial net primary productivity and the importance of the $\mathrm{CO}_{2}$ physiological effect in determining the hydrologic cycle response to geoengineering. Future efforts will endeavor to address these gaps, as well as encourage cooperation with the chemistry modeling communities, the impact assessment communities, and other groups interested in model output.

Citation: Kravitz, B., A. Robock, P. M. Forster, J. M. Haywood, M. G. Lawrence, and H. Schmidt (2013), An overview of the Geoengineering Model Intercomparison Project (GeoMIP), J. Geophys. Res. Atmos., 118, 13,103-13,107, doi:10.1002/2013JD020569.

\section{Introduction}

[2] Solar geoengineering, also called Solar Radiation Management, is the deliberate reflection of sunlight back to space, which has been proposed as a means of temporarily alleviating some of the effects of anthropogenic greenhouse gas emissions [e.g., Budyko, 1974; Crutzen, 2006]. The Royal Society [Shepherd et al., 2009] performed an initial assessment of geoengineering knowledge and outlined particular gaps in understanding of the expected effects of solar geoengineering. Their first and foremost conclusion was that the most effective way of alleviating future climate change is by reducing greenhouse gas emissions, and as such, solar geoengineering should only be applied temporarily and as a complement to aggressive mitigation and/or carbon dioxide removal. However, because society may decide to implement solar geoengineering in the future to meet particular climate goals, they recommended that significant effort be spent on characterizing the benefits, side effects, and risks.

\footnotetext{
${ }^{1}$ Atmospheric Sciences and Global Change Division, Pacific Northwest National Laboratory, Richland, Washington, USA.

${ }^{2}$ Department of Environmental Sciences, Rutgers University, New Brunswick, New Jersey, USA.

${ }^{3}$ School of Earth and Environment, University of Leeds, Leeds, UK.

${ }^{4}$ Met Office Hadley Centre, Exeter, UK.

${ }^{5}$ College of Engineering, Mathematics, and Physical Sciences, University of Exeter, Exeter, UK.

${ }^{6}$ Institute for Advanced Sustainability Studies, Potsdam, Germany.

${ }^{7}$ Max Planck Institute for Meteorology, Hamburg, Germany.

Corresponding author: B. Kravitz, Atmospheric Sciences and Global Change Division, Pacific Northwest National Laboratory, P. O. Box 999 MSIN K9-24, Richland, WA 99352, USA. (ben.kravitz@pnnl.gov)

(C)2013. American Geophysical Union. All Rights Reserved. 2169-897X/13/10.1002/2013JD020569
}

[3] Lenton and Vaughan [2009] found that "only stratospheric aerosol injections, albedo enhancement of marine stratocumulus clouds, or sunshades in space have the potential to cool the climate back toward its preindustrial state." The Geoengineering Model Intercomparison Project [GeoMIP; Kravitz et al., 2011] experiments presented in this special issue evaluate the first and the third of these proposed geoengineering schemes. Kravitz et al. [2013b] describes new proposed GeoMIP experiments to evaluate the second scheme. No technology currently exists to implement any of these schemes immediately, and GeoMIP research will help society to decide whether investment in the development of such technologies for specific schemes is advised.

[4] Coupled atmosphere-ocean global climate models provide the most comprehensive assessments for future climate scenarios, and as such, they are the best tools available for assessing the expected effectiveness and side effects of solar geoengineering. Regardless of whether field experiments will be conducted, extensive computer modeling research to determine the environmental impacts will be necessary to determine the expected climate effects of geoengineering and to provide independent advice in governance of any field experiments or practical deployment. Currently, there are no governance structures in place to assess or regulate solar geoengineering field experiments, and it may be that some proposed experiments would essentially require full-scale implementation or deployment over long periods of time to overcome a low signal-to-noise ratio [Robock et al., 2010; MacMynowski et al., 2011]. Thus, climate modeling studies are likely to be the workhorse of any community trying to understand geoengineering effects and impacts for some time. However, this also implies that any shortcomings of climate 
models in assessing future climate change will also be present in assessments of the effects of solar geoengineering.

[5] Some previous studies have shown that the side effects from solar geoengineering can be quite severe. Trenberth and Dai [2007] and Robock et al. [2008] showed that injection of stratospheric sulfate aerosols could weaken the hydrologic cycle, particularly in monsoon regions. Geoengineering with stratospheric sulfate aerosols could also enhance ozone depletion and delay recovery of the Antarctic ozone hole by 30-70 years [Tilmes et al., 2008]. However, the increased diffuse light from these aerosols could enhance plant growth; after the 1991 eruption of Mount Pinatubo, the land carbon uptake increased by $\sim 1 \mathrm{Pg} \mathrm{a}^{-1}$ over 2 to 3 years after the eruption [Jones and Cox, 2001; Mercado et al., 2009], although this increase can only account for $\sim 0.2 \mathrm{Pg} \mathrm{a}^{-1}$ of the long-term average terrestrial carbon uptake [Sarmiento et al., 2010].

[6] Many of the past results were obtained using single climate models. Although these results are helpful and insightful, they remain ambiguous as to whether the findings are robust or whether they are artifacts or characteristics of the particular models performing the simulations. Also, the lack of common setups makes comparison of the results across various studies difficult. For example, Rasch et al. [2008] compared results from two models, showing different precipitation effects in each model. However, the results are not directly comparable, as both models used different greenhouse gas trajectories and different amounts of stratospheric sulfate aerosol injection. The work of Jones et al. [2010] was the first comparison of two models that had performed nominally similar geoengineering experiments, but the models disagreed on broad features of the precipitation response to stratospheric sulfate aerosol geoengineering.

[7] Uncertainties regarding robust model response to increasing $\mathrm{CO}_{2}$ concentrations, specifically related to future projections of climate change, were a motivation for the Coupled Model Intercomparison Project [Meehl et al., 2000], which has been quite successful at both uniting climate modeling groups under a framework of common experiments and vastly improving knowledge about the climate system. GeoMIP has a similar aim, uniting climate modeling groups in conducting standardized geoengineering experiments [Kravitz et al., 2011]. Through this standardization, dependence of the results on any one model parameterization or representation of a given process can be reduced, allowing for determination of robust climate model response to solar geoengineering. This framework aids in directly addressing this research gap, noted in the Royal Society Report [Shepherd et al., 2009].

[8] Although GeoMIP has policy relevance, as even results from highly idealized experiments can provide significant basic understanding for use in analyzing more realistic scenarios [Good et al., 2013], GeoMIP is not policy prescriptive. The experiments conducted under the auspices of GeoMIP are representative of some of the radiative effects of certain methods of conducting solar geoengineering. However, the geoengineering scenarios explored in GeoMIP do not include socioeconomic feedbacks on climate and, as such, are inadequate for predicting how geoengineering would be accomplished should society develop the will to undertake it. Moreover, while GeoMIP addresses important research areas, the results obtained from this project cannot characterize all uncertainties, including the well-known difficulty in extrapolating model results to realworld climate response. Through this project, we hope to narrow some research gaps, while others will inevitably grow, and new ones will likely open up.

\section{Experiment Design and Participation}

[9] The current suite of experiments, on which most of the analysis in this special issue is based, consists of four standardized solar geoengineering experiments involving a uniform reduction of insolation (solar irradiance is multiplied by a factor less than 1.0 in every model column) or creation of a layer of stratospheric sulfate aerosols [Kravitz et al., 2011]. The simplest experiment, G1, involves balancing the top-of-atmosphere radiative perturbation from an abrupt quadrupling of $\mathrm{CO}_{2}$ concentrations from preindustrial levels with a uniform insolation decrease. G2 involves a time-dependent insolation decrease to offset the radiative flux perturbation from a scenario in which $\mathrm{CO}_{2}$ concentrations increase by $1 \%$ per year from preindustrial levels. G3 is the most complicated experiment, in which top-of-atmosphere radiative forcing over the period 2020-2070 of an RCP4.5 (representative concentration pathway resulting in $4.5 \mathrm{~W} \mathrm{~m}^{-2}$ radiative forcing [Taylor et al., 2012]) scenario is returned to 2020 levels via stratospheric injection of sulfate aerosols or aerosol precursors. G4 involves stratospheric injection of $5 \mathrm{Tg} \mathrm{SO}_{2} \mathrm{a}^{-1}$ over the period 2020-2070 of an RCP4.5 scenario. All experiments are specified to be run for 50 years, but in experiments G2, G3, and G4, geoengineering is abruptly ceased after 50 years, and then the simulation is run for an additional 20 years to evaluate the termination effect [e.g., Wigley, 2006; Jones et al., 2013]. The first GeoMIP study [Schmidt et al., 2012] used only four climate models to evaluate G1 results, but the number of fully coupled atmosphere-ocean general circulation models participating in experiments $\mathrm{G} 1, \mathrm{G} 2, \mathrm{G} 3$, and $\mathrm{G} 4$ has thus far increased to $13,12,5$, and 7 , respectively (Table 1 ). Additionally, one coupled chemistry-climate model has conducted G3, and two have conducted G4.

[10] An additional proposed experiment, called G3solar, has a similar setup to experiment G3, but the offset is performed via uniform reduction of insolation instead of stratospheric sulfate aerosol layers. The purpose of this simulation is to intercompare the effects of solar reduction and stratospheric aerosol injection, particularly related to effects on chemistry. G3solar has only been performed by three modeling groups, but more are expected over the coming months.

[11] A new suite of three experiments representing sea spray geoengineering and marine cloud brightening is described in this special issue [Kravitz et al., 2013b], following a study conducted with three European models as part of the Implications and Risks of Engineering Solar Radiation to Limit Climate Change project (K. Alterskjær et al., The transient response in three Earth System Models to a cancellation of 21 st century RCP4.5 forcing through sea salt injections into the low-latitude marine boundary layer, submitted to Journal of Geophysical Research, 2013). Participation has been pledged by multiple modeling groups.

\section{Current Knowledge and Research Gaps}

[12] GeoMIP has thus far provided insight into fundamental processes governing climate model response to geoengineering, highlighting robust features of model response. For example, 
Table 1. Models Participating in GeoMIP

\begin{tabular}{|c|c|c|c|c|c|c|c|c|}
\hline \multirow[b]{2}{*}{ Model } & \multirow[b]{2}{*}{ Stratospheric Aerosols } & \multirow[b]{2}{*}{ Ozone } & \multirow{2}{*}{$\begin{array}{l}\text { Solar Constant } \\
\quad\left(\mathrm{W} \mathrm{m}^{-2}\right)\end{array}$} & \multicolumn{5}{|c|}{$\begin{array}{l}\text { Number of Ensemble } \\
\text { Member Run }\end{array}$} \\
\hline & & & & G1 & G2 & G3 & G4 & G3solar \\
\hline BNU-ESM & Prescribed & Prescribed & 1365.89 & 2 & 3 & 1 & 1 & \\
\hline CanESM2 & Prescribed & Prescribed & 1365.00 & 3 & 3 & & 3 & \\
\hline CESM-CAM5.1-FV & Prescribed & Prescribed & 1361.00 & 1 & 1 & & & \\
\hline CCSM4 (CESM-CAM4) & $\begin{array}{l}\text { Prescribed (G1, G2, G3solar), } \\
\text { generated from } \mathrm{SO}_{2} \text { injection via } \\
\text { bulk aerosol scheme }(\mathrm{G} 3, \mathrm{G} 4)\end{array}$ & $\begin{array}{l}\text { Prescribed (G1, G2, G3solar), } \\
\text { calculated (G3, G4) }\end{array}$ & 1361.00 & 2 & 3 & & & 3 \\
\hline CSIRO Mk3L & $\begin{array}{l}\text { None (simulated as reductions } \\
\text { in solar irradiance) }\end{array}$ & Prescribed (per AMIP II) & 1365.00 & 3 & 3 & & 3 & 3 \\
\hline EC-Earth & Prescribed & Prescribed & $\begin{array}{l}1361.00 \text { (varies with } \\
\text { solar cycle) }\end{array}$ & 1 & & & & \\
\hline GISS-E2-R & Generated from $\mathrm{SO}_{2}$ injection & $\begin{array}{l}\text { Prescribed (G1 and G2), calculated } \\
\text { (G3 and G4) }\end{array}$ & 1366.00 & 3 & 3 & 3 & 3 & \\
\hline HadCM3 & Prescribed $\mathrm{SO}_{2}$ or AOD & Fixed & 1365.00 & 3 & 3 & & & \\
\hline HadGEM2-ES & Generated from $\mathrm{SO}_{2}$ injection & Specified & 1365.00 & 1 & 3 & 3 & 3 & 3 \\
\hline IPSL-CM5A-LR & Prescribed AOD & Calculated & 1365.70 & 1 & 1 & 1 & & \\
\hline MIROC-ESM & Prescribed AOD & Prescribed & 1366.00 & 1 & 1 & & 1 & \\
\hline MIROC-ESM-CHEM & $\begin{array}{l}\text { Prescribed AOD, surface area } \\
\text { density of sulfate aerosols used } \\
\text { in heterogeneous chemistry is } \\
\text { calculated based on AOD }\end{array}$ & Calculated & $\begin{array}{l}1366.00 \text { (varies with } \\
\text { solar cycle) }\end{array}$ & & & & 4 & \\
\hline MPI-ESM-LR & $\begin{array}{l}\text { Prescribed AOD; AOD generated } \\
\text { from } \mathrm{SO}_{2} \text { injection into } \\
\text { microphysical model }\end{array}$ & Prescribed & 1361.37 & 1 & 1 & 3 & & \\
\hline NorESM1-M & Prescribed & Prescribed & $\begin{array}{l}1360.89 \text { (varies with } \\
\text { solar cycle) }\end{array}$ & 1 & 1 & & & \\
\hline$U L A Q$ & Generated from $\mathrm{SO}_{2}$ injection & Calculated & 1366.05 & & & 2 & 2 & \\
\hline GEOSCCM & $\begin{array}{l}\text { Generated from } \mathrm{SO}_{2} \text { injection via } \\
\text { bulk aerosol scheme; surface } \\
\text { area density for heterogeneous } \\
\text { chemistry calculated from } \mathrm{SO}_{4} \text { mass }\end{array}$ & Calculated & 1365.00 & & & & 2 & \\
\hline
\end{tabular}

${ }^{a}$ Entries in roman are fully coupled atmosphere-ocean general circulation models, and entries in italics are coupled chemistry-climate models. Descriptions of atmospheric, oceanic, and land surface components in each model and references to each model are given by Kravitz et al. [2013a], Table 1.

the effects of uniform solar reduction on temperature are well known and robust; although geoengineering could return globally averaged temperatures to preindustrial levels, the tropics would be overcooled and the poles undercooled [Schmidt et al., 2012; Kravitz et al., 2013a]. By the nature of these simulations, feedback associated with temperature increases is suppressed, and a single forcing mechanism is perturbed in GeoMIP rather than the multitude of forcing mechanisms that are perturbed in RCP scenarios; as such, temperature and hydrologic cycle features in GeoMIP show a high degree of model agreement. None of the participating models shows the ability to return both temperature and precipitation to preindustrial levels from a world with high $\mathrm{CO}_{2}$ concentrations; returning globally averaged temperature to preindustrial levels results in overdrying [Tilmes et al., 2013]. Uniform insolation reduction is more effective in reducing changes in temperature extremes than precipitation extremes (C. L. Curry et al., A multi-model examination of climate extremes in an idealized geoengineering experiment, submitted to Journal of Geophysical Research, 2013). Geoengineering offsets the intensification of the hydrologic cycle, particularly suppressing the "rich get richer" [e.g., Held and Soden, 2006] effect of increased $\mathrm{CO}_{2}$ in which areas already receiving intense precipitation events receive even more extreme events [Tilmes et al., 2013]. An analysis of the surface and atmospheric energy budgets shows that changes in precipitation in experiment G1 can be explained mostly by changes in evaporation, suggesting that changes in moisture convergence due to changes in mean circulation are small (B. Kravitz et al., An energetic perspective on hydrological cycle changes in the Geoengineering Model Intercomparison Project (GeoMIP), submitted to Journal of Geophysical Research, 2013). All participating models agree that the rate of climate change experienced if geoengineering were to abruptly cease would be very large, as the global mean temperature returns in just a few years (on the same order as the response time of the upper ocean) to approximately what it would have been if geoengineering had never been performed; the regional rates of change in parameters such as temperature and precipitation can even be many times larger than the global rate of change [Jones et al., 2013]. In G3 and G4, polar UVB radiation increases by $5 \%$ annually, with a peak of $12 \%$ in the spring (G. Pitari et al., Stratospheric ozone response in experiments G3 and G4 of the Geoengineering Model Intercomparison Project (GeoMIP), submitted to Journal of Geophysical Research, 2013). It is beyond the remit of this introductory article to recount everything that has been learned from GeoMIP thus far, but the current state of knowledge has grown since the inception of GeoMIP, improving confidence in the understanding of the expected climate effects of geoengineering.

[13] GeoMIP has highlighted several important research gaps, however. For example, models not including a nitrogen cycle show a much higher increase in terrestrial net primary productivity, largely due to $\mathrm{CO}_{2}$ fertilization, than models that include a nitrogen cycle [Jones et al., 2013]. The $\mathrm{CO}_{2}$ physiological effect, in which plants close their stomata in 
response to increased $\mathrm{CO}_{2}$ concentrations, appears to be as important as the radiative effects on the hydrologic cycle and surface energy budget [Fyfe et al., 2013; Tilmes et al., 2013]; perturbed physics ensemble simulations have highlighted this effect as a key source of uncertainty in the climate response to solar reductions (P. J. Irvine et al., Identifying key uncertainties for sunshade geoengineering by comparing the GeoMIP ensemble and a perturbed parameter ensemble, submitted to Journal of Geophysical Research, 2013). However, GeoMIP cannot currently assess the strength of the $\mathrm{CO}_{2}$ physiological effect. Additionally, experiment G1 shows that solar reduction can prevent most of the Arctic averaged sea ice loss that would be experienced in a high- $\mathrm{CO}_{2}$ world, although regional features show strong differences [Kravitz et al., 2013a] (see also J. C. Moore et al., Arctic sea ice and atmospheric circulation under the GeoMIP G1 scenario, submitted to Journal of Geophysical Research, 2013). However, these simulations are begun from a climate in steady state and completely balance top-of-atmosphere radiative flux changes. The climate still experiences Arctic sea ice loss in G3 and G4 in which the top-of-atmosphere radiative flux is not in balance, indicating a need to compare transient simulations with simulations begun from steady state (M. Berdahl et al., Arctic cryosphere response in the Geoengineering Model Intercomparison Project (GeoMIP) G3 and G4 scenarios, submitted to Journal of Geophysical Research, 2013). Further explorations of geoengineering could consider climate differences between geoengineering applied to a steady state versus geoengineering applied to a transient state.

[14] The GeoMIP framework has also spawned a number of variants. A first comparison of G3-type simulations uses different solar geoengineering techniques with a single model. The above-mentioned overdrying would be stronger for aerosol-based methods than for sunshades in space [Niemeier et al., 2013], although this result will need to be confirmed in the multimodel framework of GeoMIP. Additionally, the generally good model agreement in GeoMIP simulations has not been compared to model agreement for simulations of anthropogenic climate change and the associated ranges of uncertainties in climate model response to forcings. Also, hemispherically asymmetric stratospheric geoengineering has been shown to dramatically change the position of the Intertropical Convergence Zone, suggesting potential perils and pitfalls of unilateral approaches [Haywood et al., 2013].

[15] Other studies included in this special issue, as well as the many planned studies that will follow, will continue to improve knowledge regarding the effects of geoengineering on the climate system, as well as discover new open areas of research. The community associated with GeoMIP has gained significant expertise in diagnosing the effects of climate forcings, promoting confidence that GeoMIP will not only advance the knowledge regarding the effects of geoengineering but will also advance the understanding of the climate system as a whole. However, the results from GeoMIP must be interpreted with caution, as there are no observations of geoengineering with which the results can be compared. That is to say, although the results from GeoMIP are concordant with the current understanding of the physical behavior of the climate system, consistency among models does not necessarily imply that the models show the correct response.

\section{Future Directions}

[16] GeoMIP will continue to provide information regarding the expected climate effects of particular methods of solar geoengineering. An important future direction of GeoMIP is to encourage use of GeoMIP output by the impact assessment community. GeoMIP output has been used to determine the impacts of geoengineering on Chinese agriculture (L. Xia et al., Stratospheric geoengineering has small impact on Chinese agriculture, submitted to Journal of Geophysical Research, 2013); this is one example of the many applications GeoMIP can have in the impacts assessment community.

[17] Additionally, GeoMIP has long engaged with the coupled chemistry-climate community. The effects of geoengineering on stratospheric ozone in general circulation models are being evaluated and compared with results from coupled chemistry models to determine discrepancies in results, highlighting areas of importance that could require improvement in model representations of geoengineering $(\mathrm{G}$. Pitari et al., Stratospheric ozone response in experiments G3 and G4 of the Geoengineering Model Intercomparison Project (GeoMIP), submitted to Journal of Geophysical Research, 2013).

[18] These two areas are examples of interactions between GeoMIP and the broader climate community. We encourage further interaction with and participation from all interested groups and fields. To obtain contact information for GeoMIP or to learn about the latest progress, visit the official GeoMIP webpage: http://climate.envsci.rutgers.edu/GeoMIP/.

[19] The solution of the global warming problem is the mitigation of greenhouse gas emissions, and a rapid program to reduce emissions will avoid the most serious consequences of climate change. However, at some point, society may consider geoengineering to avoid dangerous anthropogenic interference with the climate system. In GeoMIP, we stress the importance of scientific knowledge, particularly in informing decision making regarding geoengineering, but we recognize that science cannot be the only contribution to policy decisions. A responsible implementation of geoengineering, if undertaken by the international community, would require assessments from a broad range of fields, including law, ethics, politics, and economics, and would require a governance structure to administrate deployment. Projects like GeoMIP are essential for further understanding the scientific basis but should be viewed as only one piece of a larger effort to understand and evaluate the benefits and risks of geoengineering.

[20] Acknowledgments. We thank all participants of the Geoengineering Model Intercomparison Project and their model development teams, the CLIVAR/WCRP Working Group on Coupled Modeling for endorsing GeoMIP, and the scientists managing the Earth System Grid data nodes who have assisted in making the GeoMIP output available. Ben Kravitz is supported by the Fund for Innovative Climate and Energy Research (FICER). The Pacific Northwest National Laboratory is operated for the U.S Department of Energy by Battelle Memorial Institute under contract DEAC05-76RL01830. Alan Robock is supported by NSF grants AGS-1157525 and CBET-1240507. Jim Haywood was supported by the joint DECC/Defra Met Office Hadley Centre Climate Programme (GA01101) and funding from the European Union Seventh Framework Programme through the EuTRACE project (306395)

\section{References}

Budyko, M. I. (1974), Climate and Life, 508 p., Academic Press, New York, New York. 


\section{KRAVITZ ET AL.: GEOMIP INTRODUCTION}

Crutzen, P. J. (2006), Albedo enhancement by stratospheric sulfur injections: A contribution to resolve a policy dilemma?, Clim. Change, 77(3-4), 211-220, doi:10.1007/s10584-006-9101-y.

Fyfe, J. C., J. N. S. Cole, V. K. Arora, and J. F. Scinocca (2013), Biogeochemical carbon coupling influences global precipitation in geoengineering experiments, Geophys. Res. Lett., 40, 651-655, doi:10.1002/grl.50166.

Good, P., J. M. Gregory, J. A. Lowe, and T. Andrews (2013), Abrupt $\mathrm{CO}_{2}$ experiments as tools for predicting and understanding CMIP5 representative concentration pathway projections, Clim. Dyn., 40(3-4), 1041-1053, doi:10.1007/s00382-012-1410-4.

Haywood, J. M., A. Jones, N. Bellouin, and D. Stephenson (2013), Asymmetric forcing from stratospheric aerosols impacts Sahelian rainfall, Nat. Clim. Change, 3, 660-665, doi:10.1038/nclimate1857.

Held, I. M., and B. J. Soden (2006), Robust responses of the hydrological cycle to global warming, J. Clim., 19, 5686-5699.

Jones, C., and P. M. Cox (2001), Modeling the volcanic signal in the atmospheric $\mathrm{CO}_{2}$ record, Glob. Biogeochem. Cycles, 15(2), 453-465, doi:10.1029/2000GB001281.

Jones, A., J. Haywood, O. Boucher, B. Kravitz, and A. Robock (2010), Geoengineering by stratospheric $\mathrm{SO}_{2}$ injection: Results from the Met Office HadGEM2 climate model and comparison with the Goddard Institute for Space Studies ModelE, Atmos. Chem. Phys., 10, 5999-6006, doi:10.5194/acp-10-5999-2010.

Jones, A., et al. (2013), The impact of abrupt suspension of solar radiation management (termination effect) in experiment G2 of the Geoengineering Model Intercomparison Project (GeoMIP), J. Geophys. Res. Atmos., 118 9,743-9,752, doi:10.1002/jgrd.50762.

Kravitz, B., A. Robock, O. Boucher, H. Schmidt, K. E. Taylor, G. Stenchikov, and M. Schulz (2011), The Geoengineering Model Intercomparison Project (GeoMIP), Atm. Sci. Lett., 12, 162-167, doi:10.1002/asl.316.

Kravitz, B., et al. (2013a), Climate model response from the Geoengineering Model Intercomparison Project (GeoMIP), J. Geophys. Res. Atmos., 118, 8320-8332, doi:10.1002/jgrd.50646.

Kravitz, B., et al. (2013b), Sea spray geoengineering experiments in the Geoengineering Model Intercomparison Project (GeoMIP): Experiment design and preliminary results, J. Geophys. Res. Atmos., 118, 1-12, doi:10.1002/jgrd.50856.

Lenton, T. M., and N. E. Vaughan (2009), The radiative forcing potential of different climate geoengineering options, Atmos. Chem. Phys., 9, 5539-5561.
MacMynowski, D. G., D. W. Keith, K. Caldeira, and H.-J. Shin (2011), Can we test geoengineering?, Energy Environ. Sci., 4, 5044-5052, doi:10.1029/C1EE01256H

Meehl, G. A., G. J. Boer, C. Covey, M. Latif, and R. J. Stouffer (2000), The Coupled Model Intercomparison Project (CMIP), Bull. Am. Meteorol. Soc., 81(2), 313-318, doi:10.1175/1520-0477(2000)081<0313:TCMIPC > 2.3.CO;2.

Mercado, L. M., et al. (2009), Impact of changes in diffuse radiation on the global land carbon sink, Nature, 458, 1014-1018, doi:10.1038/nature07949.

Niemeier, U., H. Schmidt, K. Alterskjær, and J. E. Kristjánsson (2013), Solar irradiance reduction via climate engineering: Impact of different techniques on the energy balance and the hydrological cycle, J. Geophys. Res. Atmos., 118, 11,905-11,917, doi:10.1002/2013JD020445.

Rasch, P. J., et al. (2008), An overview of geoengineering the climate using stratospheric sulfate aerosols, Phil. Trans. Roy. Soc. A, 366, 4007-4037, doi:10.1098/rsta.2008.0131.

Robock, A., L. Oman, and G. L. Stenchikov (2008), Regional climate responses to geoengineering with tropical and Arctic $\mathrm{SO}_{2}$ injections, J. Geophys. Res., 113, D16101, doi:10.1029/2008JD010050.

Robock, A., M. Bunzl, B. Kravitz, and G. Stenchikov (2010), A test for geoengineering?, Science, 327, 530-531, doi:10.1126/science.1186237.

Sarmiento, J. L., et al. (2010), Trends and regional distributions of land and ocean carbon sinks, Biogeosciences, 7, 2351-2367, doi:10.5194/bg-7-2351-2010.

Schmidt, H., et al. (2012), Solar irradiance reduction to counteract radiative forcing from a quadrupling of $\mathrm{CO}_{2}$ : Climate responses simulated by four earth system models, Earth Sys. Dyn., 3, 63-78, doi:10.5194/esd-3-63-2012.

Shepherd, J., et al. (2009), Geoengineering the climate: Science, governance, and uncertainty, Royal Society Policy document 10/09, $82 \mathrm{pp}$

Taylor, K. E., R. J. Stouffer, and G. A. Meehl (2012), An overview of CMIP5 and the experiment design, Bull. Am. Meteorol. Soc., 93, 485-498, doi:10.1175/BAMS-D-11-00094.1.

Tilmes, S., R. Müller, and R. Salawitch (2008), The sensitivity of polar ozone depletion to proposed geoengineering schemes, Science, 320(5880), 1201-1204, doi:10.1126/science.1153966.

Tilmes, S., et al. (2013), The hydrological impact of geoengineering in the Geoengineering Model Intercomparison Project (GeoMIP), J. Geophys. Res. Atmos.., 118, 1-23, doi:10.1002/jgrd.50868.

Trenberth, K. E., and A. Dai (2007), Effects of Mount Pinatubo volcanic eruption on the hydrological cycle as an analog of geoengineering, Geophys. Res. Lett., 34, L15702, doi:10.1029/GL2007GL030524.

Wigley, T. M. L. (2006), A combined mitigation/geoengineering approach to climate stabilization, Science, 314(5798), 452-454, doi:10.1126/science.1131728. 